\title{
Optical absorption and luminescence spectra of 2,5-di-(2-benzoxazolyl)phenol in the solid state
}

\author{
Syetov Y. \\ Department of Solid State Physics and Optoelectronics, Oles Honchar Dnipro \\ National University, 72 Gagarin Ave., 49010 Dnipro, Ukraine, \\ e-mail:setov2003@yahoo.com
}

Received: 03.05 .2017

\begin{abstract}
Optical absorption and luminescence spectra of 2,5-di-(2-benzoxazolyl)phenol in its solid state are measured and analyzed. The photoluminescence spectrum of this material is found to exhibit both low- and high-frequency fluorescence bands in the solid state. The dual fluorescence observed is caused by close energies of enol and keto structures in the excited states. The changes found in the fluorescence spectrum are attributed to distortion of molecule in the excited state.
\end{abstract}

Keywords: excited-state intramolecular proton transfer, molecular crystals, luminescence

PACS: $78.55 \mathrm{Kz}$

UDC: $538.958,543.42$

\section{Introduction}

2,5-di-(2-benzoxazolyl)phenol abbreviated hereafter as DBP (see Fig. 1) is an organic luminescent substance that demonstrates efficient fluorescence in the visible region and a large Stokes shift [1]. This shift is caused by a photoinduced excited-state inramolecular proton transfer (ESIPT) which transforms the molecule from enol to keto structure. Spectroscopic studies of the ESIPT in DBP have earlier been performed for the solution, the gas phase and the polymer matrices. Besides, the fluorescence with a large Stokes shift originated from keto form of the molecule and a weak fluorescence with a normal Stokes shift have been found for the solution and the polymer matrices $[2,3]$. The weak fluorescence has been attributed to the structure that does not undergo the ESIPT. Presumably, it is a rotamer with an $\mathrm{OH}$... O intramolecular hydrogen bond [2]. In the present work we study for the first time both the optical absorption and the luminescence spectra of DBP in its solid state.

\section{Experimental and computational details}

A sample of DBP studied in this work was kindly provided by Prof. Joel M. Kauffman (the University of the Sciences in Philadelphia, PA). The polycrystalline powder was obtained by evaporating solution in $\mathrm{CCl}_{4}$ at the room temperature. The measurements for the solution were performed in $\mathrm{CCl}_{4}$, with the concentration $2 \cdot 10^{-6} \mathrm{M}$. The absorption spectra were measured using a Shimadzu UV-3100 spectrophotometer with the resolution of $1 \mathrm{~nm}$. The absorption spectrum of solid-state DBP was measured in a $\mathrm{KBr}$ pellet. The fluorescence spectra were recorded using a Jasny spectrofluorimeter [4] with the resolution of $4 \mathrm{~nm}$ at the room temperature and the excitation 
wavelength of $336 \mathrm{~nm}$. A front-face illumination of the sample was used. Finally, quantum chemical calculations were performed with GAMESS $[5,6]$ and ORCA $[7,8]$ program packages that employed the methods associated with density functional theory and time-dependent density functional theory.

The geometry of the structures was obtained with a B3LYP functional and 6-31G $(\mathrm{d}, \mathrm{p})$ basis set followed by single-point energy calculations with B2PLYP functional and SVP basis set. Additional single-point calculations are needed for inclusion of double excitations. It has been found [9] that the calculations with the B3LYP functional yield a qualitatively wrong result predicting the energy of the enol structure by ca. $0.14 \mathrm{eV}$ lower than that for the keto structure. This result implies that the short-wavelength fluorescence arisen from the enol structure should dominate, which contradicts the available experimental evidence $[2,3]$.

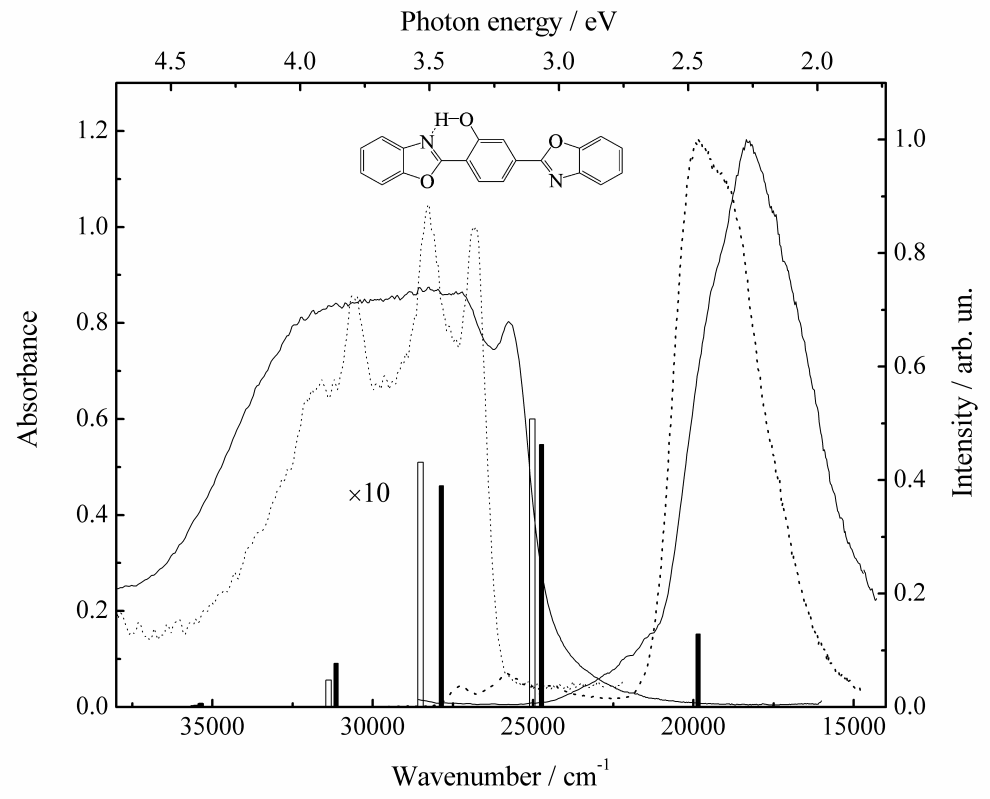

Fig. 1. Molecular structure, absorption and normalized luminescence spectra of DBP as measured in the solid state (solid line) and the solution (dashed line). The vertical bars indicate vertical transitions calculated with the TDDFT B2PLYP method red-shifted by $0.3 \mathrm{eV}$; the height is proportional to the oscillator strength. The filled bars represent the transitions for the structures I and IV and empty bars for the structure III.

\section{Results and discussion}

The absorption spectrum of DBP in the solution reveals a single band in the region $3.2-4.5 \mathrm{eV}$ with a clear vibronic structure (see Fig. 1). The corresponding peaks are located at 3.33, 3.51, 3.79 and $3.94 \mathrm{eV}$. Here DBP exhibits a dual fluorescence: a weak band with the vibronic components at $3.02,3.20$ and $3.38 \mathrm{eV}$, and a strong band with large Stokes shift. It has a distinguishable vibronic structure with the components located at 2.46 and $2.36 \mathrm{eV}$. The spectra for the solid state differ substantially from those found for the solution. One can observe a sharp peak in the absorption spectrum at $3.19 \mathrm{eV}$ and a wide band in the range $3.28-4.30 \mathrm{eV}$. The fluorescence spectrum consists of a weak band located at $2.75 \mathrm{eV}$, which is overlapped with an intense band peaked at $2.27 \mathrm{eV}$ which manifests a large Stokes shift and a shoulder at about $2.38 \mathrm{eV}$ (see Fig. 1). The absorption and luminescence spectra of DBP obtained for the solution are analogous to those reported in Ref. [3] for the solution in 3-methylpentane. 


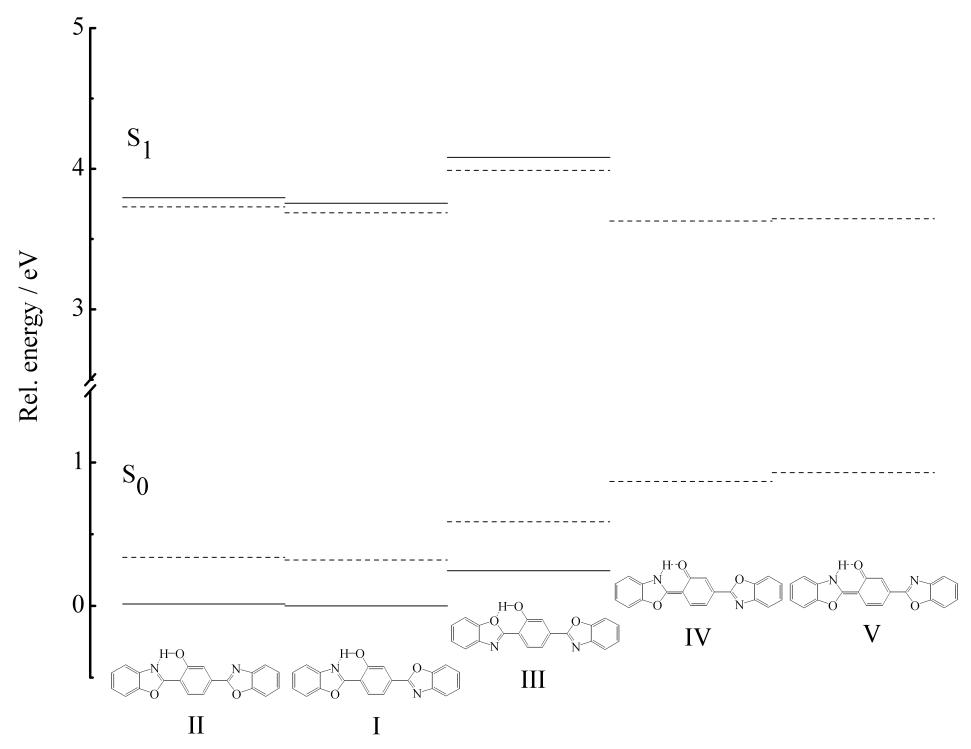

Fig. 2. Calculated electronic energy of rotameric and tautomeric species of an isolated molecule of DBP. The solid lines represent the energies of the structures optimized in the ground state and the dashed lines correspond to those optimized in the first-excited singlet state.

The molecule of DBP can exist in several conformations that differ by relative orientation of benzoxazole moieties (see Fig. 2). The energy levels calculated for different structures in the ground and first excited states are shown in Fig. 2 and the vertical transition energies are presented in Fig. 1. It should be noted that the calculations overestimate the transition energies by $0.3 \mathrm{eV}$, although this overestimation is rather systematic (see Fig. 1). Our calculations show that the absorption band consists of two electronic transitions. The vibronic bands located at 3.33 and $3.51 \mathrm{eV}$ are related to $\mathrm{S}_{0}-\mathrm{S}_{1}$ transition, whereas the bands peaked at 3.79 and $3.94 \mathrm{eV}$ correspond to $\mathrm{S}_{0}-\mathrm{S}_{2}$ transition. The energy of the structure formed by rotation of non-hydrogen-bridged moiety (II) is only a little $(\sim 0.01 \mathrm{eV})$ different, while the corresponding spectral components cannot be distinguished using the room-temperature measurements. The energy difference of the enol and keto structures in the excited state is $0.06 \mathrm{eV}$ so that the large Stokes shift in the fluorescence is caused by the energy difference of about $0.87 \mathrm{eV}$ in the ground state. Nevertheless, the structured weak band observed at $3.2 \mathrm{eV}$ comprises, at least partly, radiation from the structure that differs from the structure I. The reason is that its component $3.38 \mathrm{eV}$ is apparently higher in energy than the first absorption band at $3.33 \mathrm{eV}$, thus contradicting the Stokes shift observed in the fluorescence. This overlap of the luminescence and the absorption leads to quenching of this band via energy transfer to surrounding molecules in the crystal. The possible origin of this weak fluorescence is a conformation with an $\mathrm{OH}$... O intramolecular hydrogen bond (the structure III). The energy of the corresponding vertical transition is calculated to be blue-shifted by $0.02 \mathrm{eV}$ with respect to the energy of the transition found for the structure I.

Finally, the quantum chemical calculations [9] demonstrate that the rotation of benzoxazole and phenol parts of the keto structure decreases the gap between the ground and first excited states, which approaches a small value, $0.28 \mathrm{eV}$. The barrier for the rotation in excited state $\mathrm{S}_{1}$ is low (the estimated value being $0.08 \mathrm{eV}$ ) and the molecule can be distorted by the crystal field in its excited state. This provides the red-shift effect observed by us and the redistribution of the intensity of vibronic components of the fluorescence with the large Stokes shift upon crystallization. 


\section{Conclusion}

The photoluminescence spectrum of 2,5-di-(2-benzoxazolyl)phenol is reported for the first time. We find that the fluorescence of this solid material differs qualitatively from the fluorescence spectrum observed for the same substance dissolved in a nonpolar solvent. Flexibility of the molecule in its excited state enables decreasing fluorescence frequency, which originates from the keto form and the crystalline environment. The above results can be utilized when fabricating new luminescent materials.

\section{References}

1. Kauffman J M and Bajwa G S, 1993. Synthesis and photophysical properties of fluorescent 2,5-dibenzoxazolylphenoles and related compounds with excited state proton transfer. J. Heterocyclic Chem. 30:1613-1622.

2. Tarkka R M and Jenekhe S A, 1996. Effects of electron delocalization on intramolecular proton transfer. Chem. Phys. Lett. 260: 533-538.

3. Vdovin A, Sepioł J, Jasny J, Kauffman J M and Mordziński A, 1998. Excited state proton transfer in jet-cooled 2,5-di-(2-benzoxazolyl)phenol. Chem. Phys. Lett. 296: 557-565.

4. Jasny J, 1978. Multifunctional spectrofluorimetric system. J. Lumin. 17: 149-173.

5. Schmidt M W, Baldridge K K, Boatz J A, Elbert S T, Gordon M S, Jensen J H, Koseki S, Matsunaga N, Nguyen K A, Su S J, Windus T L, Dupuis M and Montgomery J A, 1993. General atomic and molecular electronic structure system. J. Comput. Chem. 14: 1347-1363.

6. Gordon M C and Schmidt M W. Advances in electronic structure theory: GAMESS a decade later. Chapter 41. In: Theory and Applications of Computational Chemistry, the First Forty Years. Ed. by Dykstra C E, Frenking G, Kim K S and Scuseria G E. Amsterdam: Elsevier (2005) p. 1167-1189.

7. Neese F, 2012. The ORCA program system. Wiley Interdiscip. Rev.: Comput. Mol. Sci. 2: $73-$ 78.

8. Grimme S and Neese F, 2007. Double hybrid density functional theory for excited states of molecules. J. Chem. Phys. 127: 154116.

9. Syetov Y, 2013. TDDFT calculations of electronic spectra of benzoxazoles undergoing excited state proton transfer. J. Fluoresc. 23: 689-696.

Syetov Y. 2017. Optical absorption and luminescence spectra of 2,5-di-(2-benzoxazolyl)phenol in the solid state. Ukr.J.Phys.Opt. 18: 139 - 142

Анотація. Досліджено та проаналізовано спектри поглинання та люмінесценції 2,5-ді-(2бензоксазоліл) фенолу в твердому стані. Встановлено, що спектр фотолюмінесиениії 2,5ді-(2-бензоксазоліл) фенолу в твердому стані містить $і$ складову з низькою частотою випромінювання, $і$ компоненту з високою частотою. Наявність двох смуг флуоресцениії обумовлена близькістю значень енергії енольної та кето-структур молекули в збудженому стані. Зміни в спектрі флуоресцениії віднесено до деформації молекули в збудженому стані. 